
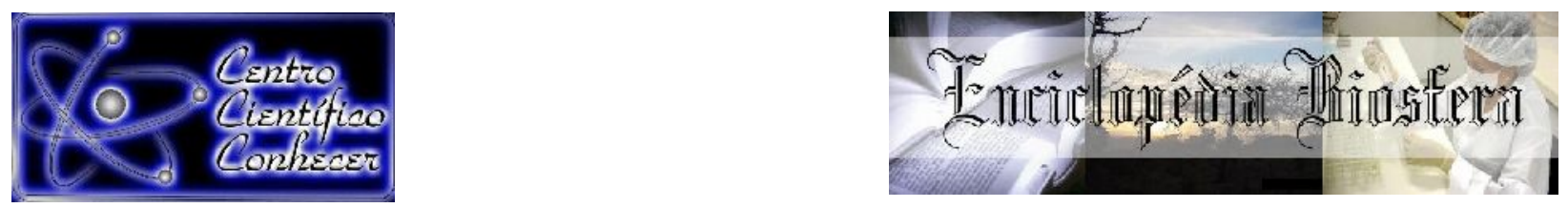

\title{
MILHO SAFRINHA CONSORCIADO COM BRAQUIÁRIA SOB PLANTIO DIRETO NO SUDOESTE DA AMAZÔNIA BRASILEIRA, ANÁLISE DE EFICIÊNCIA ECONÔMICA, SAFRA 2017/2018
}

\footnotetext{
Simone Marçal Quintino ${ }^{1}$, Rodrigo da Silva Ribeiro ${ }^{2}$, Alexandre Martins Abdão dos Passos ${ }^{3}$

${ }^{1}$ Professora de Administração de empresas, Universidade Federal de Rondônia. Cacoal, Rondônia, Brasil.

${ }^{2}$ Engenheiro Agrônomo, mestre em Ciências Ambientais pela Universidade Federal de Rondônia, Porto Velho, Brasil.

${ }^{3}$ Pesquisador da Embrapa Milho e Sorgo, Sete Lagoas, MG, Brasil. E-mail: alexandre.abdao@embrapa.br
}

Recebido em: 04/10/2019 - Aprovado em: 30/11/2019 - Publicado em: 15/12/2019 DOI: 10.18677/EnciBio 2019B39

\begin{abstract}
O planejamento e o controle dos custos de produção são fundamentais para que o produtor rural obtenha retornos satisfatórios e o auxilie nas tomadas de decisão. Objetivou-se realizar uma análise econômica da atividade de milho safrinha em sistema plantio direto, consorciado com a braquiária, na região norte no estado de Rondônia, na cidade de Porto Velho, safra 2017/2018. Para a obtenção dos custos, aplicou-se a multiplicação da matriz de coeficientes técnicos pelo vetor de preços dos fatores para a safra 2017/2018. Os valores utilizados para a formação dos custos totais e variáveis de produção e análise de indicadores de eficiência financeira e econômica foram os observados na região de Porto Velho em fevereiro de 2018 (custo) e agosto de 2018 (receita). O custo total foi estimado em $R \$$ 2.377,18 $\mathrm{ha}^{-1}$. Dentre os insumos, o fertilizante foi 0 item mais elevado, correspondendo a $35,3 \%$ do custo total, seguido das sementes de milho, com $17,9 \%$. O ponto de nivelamento para o milho foi estimado em $70,33 \mathrm{sc} \mathrm{ha}^{-1}$. A Relação Benefício Custo $(B / C)$ foi favorável de 1,05. A Margem de Contribuição obtida foi positiva com valor de $\mathrm{R} \$ 254,36$. Conclui-se que a cultura do milho foi suficiente para pagar a atividade e a formação de pasto para o período de entressafra. $O$ cultivo do milho em sucessão à soja safra em condições de plantio direto, mostrou-se economicamente viável, mesmo com margem mínima de lucratividade.
\end{abstract}

RESUMO

PALAVRAS-CHAVE: Amazônia, Integração-Lavoura-Pecuária, Sustentabilidade

\section{ECONOMIC ANALYSIS OF MAIZE INTERCROPPED WITH BRACHIARIA UNDER NO-TILLAGE SYSTEM IN THE SOUTHWEST OF THE BRAZILIAN AMAZONIA, AGRICULTURAL YEAR 2017/2018}

\begin{abstract}
Planning and control of production costs are fundamental for the rural producer to achieve adequate profits and support him in decision making. The objective of this study was to carry out an economic analysis of the cropping corn under no-tillage
\end{abstract}


system, intercropped with the brachiaria brizantha, in the northern region of the state of Rondônia, in the city of Porto Velho, for the 2017/2018 crop season. To find the expenses, it applied the multiplication of the coefficient matrix by the price vector of the factors related to the 2017/2018 year. The values used for the composition of production costs and analysis of economic efficiency indicators were those in found in Porto Velho in February 2018 (cost) and August 2018 (revenue). The total cost was estimated at $\mathrm{R} \$ 2,377.18 \mathrm{ha}^{-1}$. Among the inputs, fertilizer was the highest share, accounting for $35.3 \%$ of the total cost, followed by corn seeds, with $17.9 \%$. The breakeven was estimated at 70.33 bags ha ${ }^{-1}$. The benefit-cost $(\mathrm{BC})$ ratio was favorable at 1.05. The Contribution Margin obtained was positive by the amount of $\mathrm{R} \$ 254.36$. It was concluded that the economic performance of corn crop, intercropped with brachiaria in offseason, was appropriate to pay for the activity and to setup pasture formation for the off-season. Corn cultivation in succession to soybean crop under no-tillage system is economically viable, even with minimal profitability margin in this part of the Brazilian Amazon.

KEYWORDS: Amazon, Integrated crop livestock systems, sustainability.

\section{INTRODUÇÃO}

O cultivo do milho em segunda safra (milho safrinha), em Rondônia vem se apresentando como relevante atividade econômica para os produtores rurais, devido a geração de renda, por se mostrar como alternativa de baixo custo e aproveitamento de recursos da safra de verão e por ser uma excelente opção para integrar lavoura com a pecuária (ZU ERMGASSEN et al., 2018). Os dados relacionados à safra 2017/2018 em Rondônia, demonstraram resultados satisfatórios aos produtores rurais, pois apesar de ocorrer uma diminuição de área plantada em relação à safra anterior, houve um incremento de $4,6 \%$ na produtividade $\left(\mathrm{kg} \mathrm{ha}^{-1}\right)$ estimada e consequentemente um acréscimo na produção resultando em aumento na renda (CONAB, 2018).

Diante desse cenário, para que o produtor rural seja capaz de obter melhores rendimentos econômicos e financeiros com o cultivo de grãos, torna-se relevante realizar uma minuciosa estimativa de custos de produção e projeção das receitas, como instrumento do processo de tomada de decisão na escolha de que atividades devem compor um sistema de produção visando à sustentabilidade econômica e financeira (KOCH et al., 2019; SILVA, et al., 2019). Ressalta-se ainda que, no caso da Amazônia, a prática agropecuária tradicional inclui o aumento de produção de forma horizontal por expansão de áreas, muitas vezes por meio de desflorestamento por queimadas, impactando negativamente 0 ambiente $e$, dessa forma a sustentabilidade ambiental de atividades agropecuárias na região (MARTHA JUNIOR et al., 2012; LEMAIRE et al., 2013).

A avaliação do desempenho econômico do milho safrinha em sistemas de produção consorciados em plantio direto é necessária para que o empreendedor rural possa medir a lucratividade e a rentabilidade de cada sistema separadamente, pois esses sistemas envolvem abordagem específica quanto à sua descrição, em razão da abrangência do processo de planejamento e das atividades de execução na esfera da unidade produtiva, de fomento (REIS et al., 2019) e políticas públicas de indução (GARRETT et al., 2017).

Destaca-se que a redução das margens de lucro ocasionada pela crescente competitividade do setor agrícola, requer maior eficiência do sistema produtivo e diminuição dos gastos utilizando os custos de produção como ferramenta da gestão 
das atividades (FALEIROS et al., 2018). Esta pesquisa teve como objetivo realizar uma análise econômica financeira de um cultivo de milho safrinha em sistema plantio direto, consorciado com a braquiária, na região norte, bioma amazônico de Rondônia, Porto Velho, safra 2017/2018.

\section{MATERIAL E MÉTODOS}

A pesquisa foi realizada em uma unidade referência tecnológica (URT) implantada na segunda safra 2017/2018 na área experimental da Embrapa Rondônia. O modelo conceitual da área engloba a semeadura da cultura da soja ou feijão-caupi na safra e milho ou sorgo consorciados com braquiária brizantha Xaraés na safra de sucessão. O capim foi semeado na linha e entrelinha do milho, com adubação apenas na linha do milho (PASSOS et al., 2017).

O milho safrinha foi semeado em sistema de plantio direto após a colheita da soja na segunda quinzena do mês de fevereiro de 2018. Entre a colheita da soja na safra e a semeadura do milho, realizou-se a dessecação da área com a herbicida Sumyzin e Glifosato distribuídos com pulverizador de barras, objetivando a preparação da área para o plantio direto das lavouras em sucessão.

Como fertilização de plantio utilizou-se $05-20-20 \mathrm{~kg} \mathrm{ha}^{-1}$ de NPK (Ca $3 \%$, S 2 $\%$, B 0,54 \%, Mn 0,6 \% e Zn 0,27 \%). Decorridos 25 dias após a semeadura (DAS), quando as plantas do milho apresentavam de três a quatro folhas expandidas, foi distribuída a fertilização em cobertura sob a forma de ureia, com reaplicação no mês de maio. As herbicidas foram aplicadas por meio de um pulverizador de barras. A Brachiaria Brizantha cv Xaraés foi semeada nas linhas e entrelinhas do milho, simultaneamente utilizando-se uma taxa de semeadura de 400 pontos de VC (valor cultural). A colheita do milho foi realizada mecanicamente em junho de 2018 . Todo o conjunto de procedimentos e/ou técnicas utilizadas na produção agropecuária são descritos e sumarizados na tabela 1.

Para a obtenção dos custos, aplicou-se a multiplicação da matriz de coeficientes técnicos pelo vetor de preços dos fatores (MARTIN et al., 1998; CONAB, 2010; GUIDUCCI et al., 2012) de safra 2017/2018. Os valores utilizados para a formação dos custos de produção e avaliação dos indicadores de eficiência financeira e econômica foram os ocorrentes na região municipal de Porto Velho/RO em fevereiro de 2018 (preços de insumos) e agosto de 2018 (venda a $R \$ 33,80$ por saca de $60 \mathrm{~kg}$ ).

O custo total de produção foi constituído pelos custos variáveis (operações mecanizadas, insumos, operações manuais e despesas administrativas), custo fixo (depreciação de máquinas, equipamentos, benfeitorias e instalações) e o custo de alternativo (remuneração da terra, do capital de custeio e fixo), calculados por hectare. Para o cálculo dos custos de produção, adotou-se a metodologia proposta por Martin et al. (1998), CONAB, (2010) e Guiducci et al. (2012). Destaca-se que não foi considerado na composição dos custos de produção do milho, os gastos referentes a pastagem.

Considerou para a composição das despesas diretas, a assistência técnica (2 $\%)$, Seguro Agrícola - Proagro (3\%), Despesas Administrativas (3 \%), Funrural (1,5 $\%)$, juros sobre o capital de custeio (5,5\% a.a - PRONAF Banco do Brasil S/A), calculados para uma área correspondente à um hectare. $\mathrm{O}$ transporte pós colheita, recebimento e secagem dos grãos foram calculados com base na produtividade (CONAB, 2010).

Para a remuneração dos fatores de produção, constituída pelos custos de 
oportunidade (MARTIN et al., 1998; CONAB, 2010), calculou-se o custo do fator terra baseado no valor do arrendamento com juros de $3 \%$ ao ano, com preço da terra ( $\mathrm{R} \$ 6.000,00$ ha $\left.^{-1}\right)$ para a região de Porto Velho (AGRIANUAL, 2018). Para o cálculo da remuneração do custeio utilizou-se a taxa de juros de 5,5\% a.a (PRONAF), e, para a remuneração do capital utilizou-se $6,14 \%$ a.a de juros com base no rendimento da Poupança (BANCO CENTRAL DO BRASIL, 2018), ambos calculados para o período de cultivo do milho safrinha (125 dias).

Os indicadores de eficiência econômica utilizados para a análise compreenderam a Renda Bruta (RB), equivalente ao valor resultante da quantidade comercializada pelo preço correspondente, sem reduções, sejam eventuais impostos incidentes ou mesmo descontos sobre o produto foco (MARTIN et al., 1998); a relação entre benefício custo $(B / C)$ corresponde à eficiência de todo o sistema de produção, obtida pela divisão das receitas e o atual valor dos custos (GUIDUCCI et al., 2012); a margem de contribuição (MC) aponta o que sobrou para cobrir os custos fixos; o ponto de nivelamento (PN) corresponde a quantidade demandada para compensar os custos de produção, obtido mediante a divisão do custo total pelo preço de venda observado no mercado. Por sua vez, o ponto de equilíbrio (PE) ou Break Even Point indica o volume de vendas no qual os custos e despesas totais são os valores das receitas totais. O custo médio de produção $\left(C T_{\text {me }}\right)$ é um indexador econômico usado para comparar o preço de venda do produto, subtraído da divisão do custo total pela quantidade produzida naquele período (CONAB, 2010; GUIDUCCI et al., 2012).

Uma análise de sensibilidade permite medir a mudança de um resultado (ou indicador) por meio da troca de cada uma das variáveis, tanto em termos relativos como absolutos (PASA et al., 2017). Adotou-se a variável preço de venda em função da produtividade necessária para superar os custos de produção, considerando três condições de maior favorabilidade, com aumento de $10 \%$, ou $20 \%$ ou $30 \%$, e três de menor favorabilidade com redução a partir de $10 \%, 20 \%$ e até o máximo de 30 \% sobre o preço de venda estimado no cenário do milho safrinha referente a safra 2017/2018.

\section{RESULTADOS E DISCUSSÃO}

O custo total mensurado para o cultivo do milho safrinha em sistema plantio direto composto pelos insumos, operações mecanizadas e manuais, depreciação, remuneração dos fatores e outras despesas foi estimado em $R \$ 2.377,18 \mathrm{ha}^{-1}$ na safra 2017/2018. Ao comparar esses custos com os da safra anterior (2016/2017), observou-se que houve um aumento percentual de 3,66 \% (PASSOS et al., 2017). A Tabela 1 apresenta a composição detalhada dos custos de produção do milho safrinha consorciado com braquiária brizantha cultivar Xaraés.

TABELA 1: Custo total de produção do milho safrinha, $\left(\mathrm{R} \$ \mathrm{ha}^{-1}\right)$, consorciado em plantio direto e integrado na região sudoeste da Amazônia safra 2017/2018. Porto Velho, RO

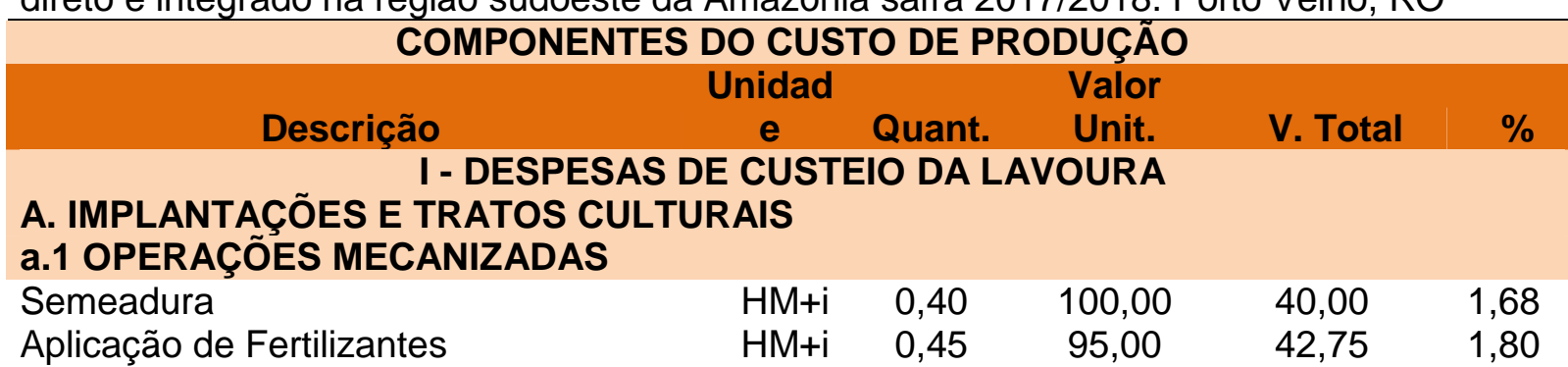


Aplicação de Herbicidas

Aplicação de inseticida

Colheita mecânica

Subtotal A.1

a.2 OPERAÇÕES MANUAIS

Aplicação de Herbicida

Aplicação de inseticida

Semeadura

Aplicação de Fertilizantes

Colheita

$\begin{array}{ccccc}\mathrm{HM}+\mathrm{i} & 0,40 & 95,00 & 38,00 & 1,60 \\ \mathrm{HM}+\mathrm{i} & 0,26 & 95,00 & 24,70 & 1,04 \\ \mathrm{HM}+\mathrm{i} & 0,40 & 150,00 & 60,00 & 2,52 \\ & & & \mathbf{2 0 5 , 4 5} & \mathbf{8 , 6 4}\end{array}$

Subtotal A.2

$\mathrm{DH}$

0,10

80,00

8,00

0,34

$\mathrm{DH}$

0,10

100,00

10,00

0,42

$\mathrm{DH}$

0,15

80,00

12,00

0,50

$\mathrm{DH} \quad 0,10$

80,00

8,00

0,34

$\mathrm{DH}$

0,15

80,00

12,00

0,50

Subtotal A (A1 + A2)

B. INSUMOS

Sementes de milho

Fertilizante cobertura (Ureia)

Fertilizante Plantio (5-20-20)

Inseticida (Imidacloprido)

Inseticida (Lambda-cialotrina)

Inseticida (Tiametoxam + Lambda-

Cialotrina)

Inseticida (Clorpirifós)

Herbicida dessecação (Glifosato)

Herbicida dessecação (Flumioxazin)

Herbicida (Atrazina)

Óleo Vegetal - adjuvante

Óleo Mineral - adjuvante

Subtotal B

TOTAL I - DESPESAS DE CUSTEIO DA LAVOURA (A+B)

II - OUTRAS DESPESAS (D)

\begin{tabular}{|c|c|c|c|c|c|}
\hline \\
\hline Assistência Técnica & $\%$ & 0,02 & $1.740,78$ & 34,82 & 1,46 \\
\hline Seguro Agrícola (Proagro) & $\%$ & 0,03 & $1.740,78$ & 52,22 & 2,20 \\
\hline Transporte Pós Colheita & sc & 72,15 & 1,00 & 72,15 & 3,04 \\
\hline Recebimento e Secagem & sc & 72,15 & 0,80 & 57,72 & 2,43 \\
\hline Despesas Administrativas & $\%$ & 0,03 & $1.740,78$ & 52,22 & 2,20 \\
\hline Juros Financiamento Custeio (5,5\% a.a.) & $\%$ & 1 & 137,82 & 137,82 & 5,80 \\
\hline Funrural $(1,5 \%)$ & $\%$ & 0,015 & $2.438,67$ & 36,58 & 1,54 \\
\hline TOTAL III - OUTRAS DESPESAS (D) & & & & 443,53 & 18,66 \\
\hline CUSTO VARIÁVEL (E): $A+B+C+D$ & & & & $2.184,31$ & 91,89 \\
\hline \multicolumn{6}{|c|}{ IV - DEPRECIAÇÃO (F) } \\
\hline Depreciação de Máquinas & $\mathrm{R} \$$ & 1 & 13,37 & 13,37 & 0,56 \\
\hline Depreciação de Equipamentos & $\mathrm{R} \$$ & 1 & 21,55 & 21,55 & 0,91 \\
\hline Depreciação de Benfeitorias e Instalações & $R \$$ & 1 & 27,00 & 27,00 & 1,14 \\
\hline TOTAL - IV DEPRECIAÇÕES (F) & & & & 61,92 & 2,60 \\
\hline CUSTO FIXO (G): & & & & 61,92 & 2,60 \\
\hline CUSTO OPERACIONAL (H): E+G & & & & $2.246,22$ & 94,49 \\
\hline \multicolumn{6}{|c|}{ V - RENDA DE FATORES (I) } \\
\hline Remuneração do Capital Fixo & $\%$ & 1 & 32,24 & 32,24 & 1,36 \\
\hline Remuneração da terra & $\%$ & 1 & 59,40 & 59,40 & 2,50 \\
\hline Remuneração do Capital de Custeio & $\%$ & 1 & 39,32 & 39,32 & 1,65 \\
\hline TOTAL V - RENDA DOS FATORES (I) & & & & 130,96 & 5,51 \\
\hline CUSTO TOTAL (J): H+I & & & & $2.377,18$ & $100 \%$ \\
\hline
\end{tabular}

$\mathrm{HM}+\mathrm{i}$ : hora máquina + implemento (equipamento); Dh: Dia homem; kg: quilograma; I: litro; t: tonelada; ml: mililitro; g: grama; sc: saca; \% percentual.

Fonte: os autores (2018) 
Os custos variáveis compostos pelos insumos, operações mecanizadas e manuais e, outras despesas, correspondem a 91,89\%, com valor estimado de $\mathrm{R} \$$ $2.184,80$ por hectare e os outros custos (fixos e renda dos fatores) representam 8,11 $\%$ do total, um valor de $R \$ 192,87$. O componente que mais influenciou o custo total foram os insumos, representando $62,48 \%$. Dentre os insumos utilizados, o fertilizante foi o item com custo mais elevado, correspondendo a 35,27 \% do custo total, seguido das sementes de milho, com 17,88 \%. A Figura 1 apresenta graficamente a decomposição dos custos de produção do milho cultivado em Sistema integrado entre lavoura e pecuária.

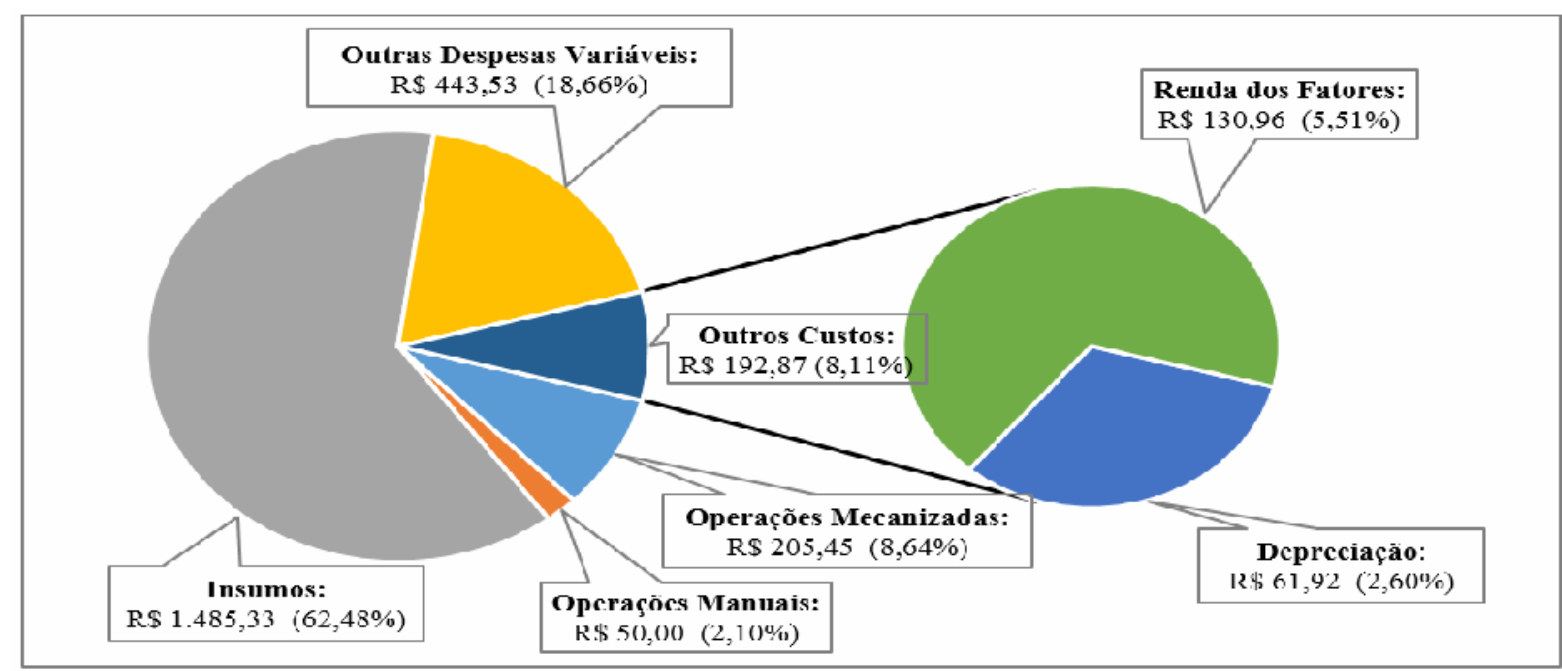

FIGURA 1: Representação gráfica dos custos de produção do milho safrinha, Safra 2017/2018 Fonte: os autores (2019)

Resultados análogos têm demonstrado que o componente insumos impactam significantemente o custo total na produção do milho safrinha. $\mathrm{Na}$ pesquisa de Richetti (2017) referente a safra $2017 / 2018$, os insumos representaram $41,39 \%$ (milho Bt), 42,95 \% (milho Bt $+\mathrm{RR}$ ) e 38,24\% (milho convencional) dos custos totais. Segundo o IFAG (2018), o componente insumos totalizou $R \$ 1.232,36 \mathrm{ha}^{-1}$, impactando os custos em 59,81\% do total, sendo que o fertilizante corresponde a $29,17 \%$ do custo total.

O milho safrinha apresentou um Custo Total Médio (CTme) de $\mathrm{R} \$ 32,91$ saca ha $^{-1}$ (Tabela 2). O CTme apresentou-se 2,6\% inferior ao preço médio de comercialização no Estado de Rondônia no mês de agosto de 2018, que foi de $R \$$ 33,80 por cada saca de $60 \mathrm{~kg}$ (EMATER-RO, 2018). Esse resultado evidencia a receita sendo suficiente para cobrir os custos de produção da atividade. O CTme em análise apresenta uma variação percentual superior de 38,2 \% em relação ao CTme estimado na safra anterior, de 2016/2017 para Porto Velho que obteve $R \$ 23,80$ (PASSOS et al., 2017).

TABELA 2: Indicadores de eficiência econômica de lavoura de milho safrinha em plantio direto na região sudoeste da Amazônia safra 2017/2018. Porto Velho, RO.

\begin{tabular}{lcc}
\multicolumn{1}{c}{ Indicador Econômico } & Unidade & Valores \\
Produtividade & Sacas & 72,15 \\
Preço de Venda (PV) & $\mathrm{R} \$ \mathrm{sc}$ & 33,80 \\
Custo Total (CT) & $\mathrm{R} \$ \mathrm{ha}^{-1}$ & $2.377,18$ \\
Custo Total Médio (CTme) & $\mathrm{R} \$ \mathrm{ha}^{-1}$ & 32,91 \\
Receita Bruta ou Renda Bruta (RB) & $\mathrm{R} \$ \mathrm{ha}^{-1}$ & $2.438,67$
\end{tabular}


Receita Líquida (RL)

$\mathrm{R} \$ \mathrm{ha}^{-1}$

61,49

Margem de Contribuição (MC)

Margem de Contribuição

$\mathrm{R} \$ \mathrm{ha}^{-1}$

254,36

Relação Benefício/Custo (B/C)

$\%$

10,43

Ponto de Nivelamento

Ponto de Equilíbrio Econômico

1,02

Fonte: os autores (2019)

70,33

Sacas

54,71

A Receita Bruta Operacional ou Renda Bruta (RB) do milho safrinha cultivado na safra $2017 / 2018$ foi estimada em $R \$ 2.438,67$ (Tabela 2 ), com uma variação inferior a 9,68 \% em relação à safra anterior (2016/2017). O preço médio da saca do milho de $60 \mathrm{~kg}$ foi estimado em $\mathrm{R} \$ 33,80$, na região de Porto Velho em agosto de 2018 (CONAB, 2018).

A produtividade do milho foi estimada em $72,15 \mathrm{sc} \mathrm{ha}{ }^{-1}\left(4.329 \mathrm{~kg} \mathrm{ha}^{-1}\right)$, apresentando uma retração de 27,85 \% comparada a safra 2016/2017 que foi de $100 \mathrm{sc} \mathrm{ha}{ }^{-1}\left(6.000 \mathrm{~kg} \mathrm{ha}{ }^{-1}\right)$, conforme Passos et al. (2017). Por sua vez, a produtividade média de Rondônia houve um aumento de 4,6 \%, safra $2017 / 2018$ (4.586 kg ha $\left.{ }^{-1}\right)$, comparada a safra 2016/2017 (4.385 kg ha-1), apesar da redução de $3,5 \%$ da área plantada em relação à safra anterior (CONAB, 2018).

A Margem de Contribuição (MC) obtida foi positiva com valor de $\mathrm{R} \$ 254,36$, indicando que ao deduzir os custos e as despesas variáveis da receita total, esses são os valores que sobraram para cobrir os custos fixos e ainda gerar lucro ao produtor rural. Em termos percentuais, cada unidade produzida contribui em 10,43\% para cobrir todos os custos e despesas fixas (Tabela 2).

Após subtrair o custo total (incluindo os custos de alternativos) e a receita total do período, o milho safrinha demonstrou uma renda líquida Total $(R L)$ positiva, atingindo $\mathrm{R} \$ 61,49 \mathrm{ha}^{-1}$, com uma variação de $80,7 \%$ inferior comparada a safra 2016/2017 (R\$318,75 ha $\left.{ }^{-1}\right)$. Segundo o IMEA (2015), a cultura do milho vem sendo impactada nos últimos anos com preços baixos e aumento de custos, causando incerteza sobre os produtores, no tocante a possíveis aumentos na área semeada. Menores rentabilidades vêm sendo cada vez mais rotineiras para os produtores de milho no Mato Grosso, decorrendo a situações de retornos negativos. milho.

A Figura 2 apresenta o Ponto de Nivelamento e o Ponto de Equilíbrio do

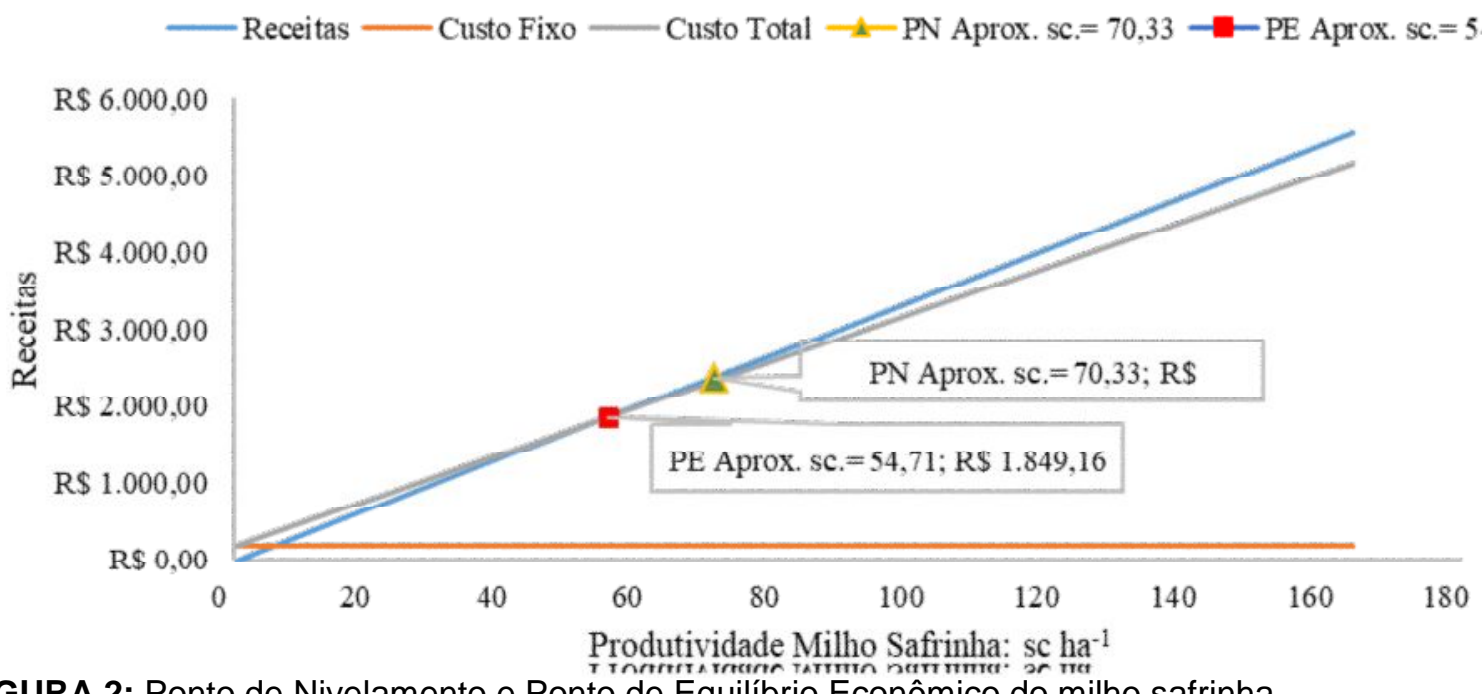

FIGURA 2: Ponto de Nivelamento e Ponto de Equilíbrio Econômico do milho safrinha Fonte: os autores (2019) 
No ponto de nivelamento para o milho, foi estimado 70,33 sacas $\mathrm{ha}^{-1}$, com uma diferença de $1,82 \mathrm{sc} \mathrm{ha}^{-1}$ em relação a produtividade estimada de $72,15 \mathrm{sc} \mathrm{ha}^{-1}$, apontando ganhos reais para o produtor. A variação percentual em relação ao ponto de nivelamento da safra anterior de 2016/2017 foi 20,08 \% inferior comparado com essa safra (PASSOS et al., 2017). O ponto de equilíbrio econômico foi estimado em $54,71 \mathrm{sc} \mathrm{ha}^{-1}$, evidenciando que ao produzir essa quantidade, as receitas se igualam aos custos. A Margem de Segurança (MS), que indicou o porcentual de redução de vendas que a propriedade podia suportar sem que tivesse prejuízo foi de $2,52 \%$.

A Razão B:C foi maior que 1 , evidenciando que as receitas foram superiores aos custos, tornando a atividade economicamente viável, conforme Vitale e Miranda (2010), um projeto é considerado economicamente viável quando apresenta relação $B: C>1$. A Razão Benefício Custo $(B / C)$ foi de 1,05 , isto é, para cada $R \$ 1,00$ investido no milho safrinha, obteve-se $R \$ 1,05$ de receita, ou seja, as receitas superam os custos em $5 \%$.

A análise de sensibilidade do milho safrinha permitiu identificar que a variável preço influencia na quantidade necessária para estimar o ponto de nivelamento da produção, conforme Tabela 3 . À medida que os preços de venda diminuem em relação ao cenário base $(-10 \%,-20 \%,-30 \%)$, a produtividade necessária para cobrir os custos de produção tende a aumentar.

TABELA 3: Cenário da Produtividade necessária para remunerar custo fixo, variável e total na cultura do milho safrinha com variação do preço de venda, Porto Velho, Rondônia.

\begin{tabular}{|c|c|c|c|c|c|}
\hline \multirow[b]{2}{*}{ Variação } & \multirow[b]{2}{*}{$\begin{array}{c}\text { Preço } \\
\mathbf{R} \$ \text { sacas }\end{array}$} & \multicolumn{4}{|c|}{ Produtividade necessária } \\
\hline & & $\begin{array}{c}\text { Custo Fixo } \\
\left(\mathrm{kg} \mathrm{ha}^{-1}\right)\end{array}$ & $\begin{array}{c}\text { Custo Variável } \\
\left(\mathrm{kg} \mathrm{ha}^{-1}\right)\end{array}$ & \begin{tabular}{|c|} 
Custo Total \\
$\left(\mathrm{kg} \mathrm{ha}^{-1}\right)$
\end{tabular} & $\begin{array}{c}\text { Total } \\
\left.\left(\text { sc }^{-1}\right)^{-1}\right)\end{array}$ \\
\hline \multicolumn{6}{|l|}{ Cenário Base } \\
\hline Preço milho sc hä & 33,80 & 342,38 & 3.877 & 4.220 & 70,33 \\
\hline \multicolumn{6}{|l|}{ Menor Favorabilidade } \\
\hline $10 \%$ a menos no preço & 30,42 & 380 & 4.308 & 4.689 & 78,15 \\
\hline $20 \%$ a menos no preço & 27,04 & 428 & 4.847 & 5.275 & 87,91 \\
\hline $30 \%$ a menos no preço & 23,66 & 489 & 5.539 & 6.028 & 100,47 \\
\hline \multicolumn{6}{|l|}{ Maior Favorabilidade } \\
\hline $10 \%$ a mais no preço & 37,18 & 311 & 3.525 & 3.836 & 63,94 \\
\hline $20 \%$ a mais no preço & 40,56 & 285 & 3.231 & 3.517 & 58,61 \\
\hline $30 \%$ a mais no preço & 43,94 & 263 & 2.983 & 3.246 & 54,1 \\
\hline
\end{tabular}

Fonte: os autores (2019)

Verificou-se que na simulação de menor favorabilidade, com redução mínima do preço de venda em $10 \%$, a produtividade necessária para suplantar todos os custos ultrapassou a produtividade estimada durante a safra, que foi de $72,15 \mathrm{sc} \mathrm{ha}^{-1}$ $\left(4.329 \mathrm{~kg} \mathrm{ha}^{-1}\right)$. Nesse cenário, seria preciso $78,15 \mathrm{sc} \mathrm{ha}^{-1}\left(4.689 \mathrm{~kg} \mathrm{ha}^{-1}\right)$ de milho para amortizar todos os custos de produção, apresentando uma variação percentual de 7,68 \% superior, comparado com o cenário base. Esse cenário evidencia que 0 preço de venda é sensível a uma redução mínima, o que resultaria em prejuízos ao produtor rural.

Para as simulações no cenário de maior favorabilidade, com aumento no preço de venda em $10 \%, 20 \%$ e $30 \%$, verificou-se que a produtividade foi 
impactada em $3.836 \mathrm{~kg} \mathrm{ha}^{-1}, 3.517 \mathrm{~kg} \mathrm{ha}^{-1}$ e $3.246 \mathrm{~kg} \mathrm{ha}^{-1}$, respectivamente. O ponto de nivelamento nesse cenário foi de $63,94 \mathrm{sc} \mathrm{ha}^{-1}, 58,61 \mathrm{sc} \mathrm{ha}^{-1}$ e $54,10 \mathrm{sc} \mathrm{ha}{ }^{-1}$, ou seja, inferior a produtividade estimada na safra $\left(72,15 \mathrm{sc} \mathrm{ha}{ }^{-1}\right)$, resultando em lucros nessa simulação.

\section{CONCLUSÃO}

Os resultados evidenciaram que a produtividade média do milho safrinha cultivado em consórcio com a braquiária e em plantio direto na safra 2017/2018, diminuiu em relação à safra 2016/2017.

O cultivo do milho em sucessão à soja safra em condições de plantio direto, mostra-se economicamente viável, mesmo com margem mínima de lucratividade.

O planejamento e o controle dos custos de produção são fundamentais para que o produtor rural obtenha retornos satisfatórios e o auxiliam nas tomadas de decisão.

\section{REFERÊNCIAS}

AGRIANUAL 2018: Anuário da agricultura brasileira. Preço de Terras. São Paulo: Informa Economics IEG/FNP. p.76 disponível em: www.informaecon-fnp.com

BANCO CENTRAL DO BRASIL. Remuneração dos Depósitos de Poupança. 2018. Disponível em: https://www4.bcb.gov.br/pec/poupanca/poupanca.asp. Acesso em 06 de novembro de 2018.

CONAB - Companhia Nacional de Abastecimento. Observatório Agrícola. Acompanhamento da safra brasileira grãos. Monitoramento Agrícola. v. 5 - safra 2017/18 n. 9 - Nono levantamento. Brasília: junho 2018.

CONAB (Brasil). Metodologia de cálculo de custo de produção da CONAB. 2010. Disponível em: http://www.conab.gov.br/conabweb/download/safra/custosproducaometodologia.pdf. Acesso em: 12 ago. 2017

EMATER-RO - Empresa Estadual de Assistência Técnica e extensão rural do estado de Rondônia. Pesquisa semanal de preços. 1a semana Agosto 2018. Disponível em: http://www.emater.ro.gov.br/ematerro/pesquisa-de-preco/. Acesso em: 01.11.2018

FALEIROS, G.D.; SANTOS, D.F.L.; CORÁ J.E.; Analysis of profitability of conservation tillage for a soybean monoculture associated with corn as an off-season crop, Cogent Food \& Agriculture, 4:1, 2018. DOI: 10.1080/23311932.2018.1429699

GARRETT, R.D.; GARDNER, T.; FONSECA, T.; MARCHAND, S.; BARLOW, J.; et al. Explaining the persistence of low income and environmentally degrading land uses in the Brazilian Amazon. Ecology and Society (2017), p. 22, Doi: 10.5751/ES09364-220327

GUIDUCCI, R. do C. N.; ALVES, E. R. de A.; LIMA FILHO, J. R.; MOTA, M. M. Aspectos metodológicos da análise de viabilidade econômica de sistemas de 
produção. In: GUIDUCCI, R. do C. N.; LIMA FILHO, J. R.; MOTA, M. M. (Ed.). Viabilidade econômica de sistemas de produção agropecuários: metodologia e estudos de caso. Brasília: Embrapa, p. 17-78.2012.

IMEA - Instituto Matogrossense de Pesquisa Agropecuária. Entendendo o mercado do milho. IMEA. 2015. Disponível em: http://www.imea.com.br/upload/pdf/arquivos/Paper_jornalistas_Milho_AO.pdf.

Acesso em: 30.10.2018

IFAG - Instituto para o fortalecimento da agropecuária de Goiás. Estimativa do Custo de Produção - Milho Safrinha. Fevereiro 2018. Disponível em: http://ifag.org.br/custos-de-producao?start=7

KOCH, N.; ZU ERMGASSEN, E. K. H. J.; WEHKAMP, J.; OLIVEIRA FILHO, F. J. B.; SCHWERHOFF, G. Agricultural Productivity and Forest Conservation: Evidence from the Brazilian Amazon, American Journal of Agricultural Economics, Volume 101, Issue 3, April 2019, Pages 919-940. Doi: https://doi.org/10.1093/ajae/aay110

LEMAIRE, G.; FRANZLUEBBERS, A.; CARVALHO, P. C. F.; DEDIEU, B. 2013. Integrated crop-livestock systems: Strategies to achieve synergy between agricultural production and environmental quality. Agriculture, Ecosystems and Environment. Volume 190, 1 June 2014, Pages 4-8. Doi: https://doi.org/10.1016/j.agee.2013.08.009Get rights and content

MARTHA JUNIOR, G.B.; ALVES, E.; CONTINI, E.; 2012. Land-saving approaches and beef production growth in Brazil. Agricultural Systems. 110 (2012) 173-177. Doi: http://dx.doi.org/10.1016/j.agsy.2012.03.001

MARTIN, N. B.; SERRA, R.; OlIVEIRA, M. D. M.; ÂNGELO, J.A.; OKAWA, H. Sistema Integrado de Custos Agropecuários - CUSTAGRI. Informações Econômicas, SP, v.28, n.1, jan. 1998. Disponível em: http://www.iea.sp.gov.br/ftpiea/ie/1998/tec1-0198.pdf

PASA, D. L.; FARIAS, J. A. A.; LAUREANO, F.; NOLASCO, B. G. Análise econômica de plantios florestais na agricultura familiar na região sul do Brasil.; Revista de Economia e Agronegócio, Viçosa, MG, v. 15, n. 2, p. 277-292, set. 2017. ISSN 2526-5539. Doi: https://doi.org/10.25070/rea.v15i2.469

PASSOS, A. M. A.; QUINTINO, S. M.; RIBEIRO, R. S.; SANTOS, B. S.; MUNIZ, R. P. Custo de Produção Estimado para a Cultura do Milho Safrinha em Consórcio com Braquiária, na Região de Porto Velho, Rondônia, Safra 2016/17. Embrapa Milho e Sorgo. Comunicado Técnico no 232. Sete Lagoas: 2017.

RICHETTI, A. Viabilidade Econômica da Cultura do Milho Safrinha 2018, em Mato Grosso do Sul. Dourados: Embrapa Agropecuária Oeste, 2017. (Embrapa Agropecuária Oeste. Comunicado técnico, 231)

REIS, J.; KAMOI, M.; LATORRACA, D.; CHEN, R.; MICHETTI, M.; et al. Assessing the economic viability of integrated crop-livestock systems in Mato Grosso, Brazil. 
$\begin{array}{lllll}\text { Renewable Agriculture and Food } & \text { Systems, } & \text { 1-12. }\end{array}$ doi:10.1017/S1742170519000280

SILVA, F. D., PERRIN, R. K; FULGINITI, L. E. (2019), The opportunity cost of preserving the Brazilian Amazon forest. Agricultural Economics, Vol. 50, Issue 2, March 2019, Pages: 219-227. doi:10.1111/agec.12478

VITALE, V.; MIRANDA, G. de M. Análise comparativa da viabilidade econômica de plantios de Pinus taeda e Eucalyptus dunnii na região centro-sul do Paraná. Revista Floresta, v.40, n.3, p. 469-476, Curitiba, 2010.

ZU ERMGASSEN, E.K.H.J; ALCÂNTARA, M.P.; BALMFORD, A.; BARIONI, L.; BEDUSCHI NETO, F.; et al.; Results from On-The-Ground Efforts to Promote Sustainable Cattle Ranching in the Brazilian Amazon. Sustainability 2018, 10, 1301. https://doi.org/10.3390/su10041301 